\title{
A Series Active Power Filter Controlled by Personal Computer
}

\author{
M. João Sepúlveda Freitas, João L. Afonso, Júlio S. Martins \\ Department of Industrial Electronics \\ University of Minho \\ Campus of Azurém - 4800-058 Guimarães (Portugal) \\ phone:+351 253 510190, fax:+351 253510189 \\ e-mail: mjs@dei.uminho.pt, jla@dei.uminho.pt,jmartins@dei.uminho.pt
}

\begin{abstract}
This paper describes work that is being done in the design and implementation of a series active power filter for electrical power quality purposes. This type of filter is able to compensate for the following voltage related problems in the power grid: short blackouts for a few cycles, voltage distortion due to harmonics on a repetitive basis, voltage unbalance in three-phase systems, voltage flicker (subharmonics) and momentary over or under voltages.
\end{abstract}

The main objective of the work described in the paper is to build a series active filter controlled by a personal computer with a standard multifunction data acquisition PCI bus card, because of its relative low cost and versatility. This PC based solution presents some difficulties since the control of a series active filter is a kind of application which requires a fast controller which that does not miss samples and where all real-time deadlines must be met each and every time, or the system will not operate properly. These characteristics imply that this application falls in the "hard real-time" control category. In the paper, some results are presented and some conclusions are taken using two different operating systems. Furthermore, a comparison with a microcontroller based implementation will be made.

\section{Keywords}

Series Active Filter, p-q Theory, Data Acquisition, Real-time Control.

\section{Introduction}

There are several causes for voltage distortion, namely, non linear loads, some types of voltage sources and thunderstorms. These problems cause instantaneous and long term effects on electrical equipment. The short term effects are malfunctioning, interferences and degradation of the performance of devices or equipments. Effects in the long run are, basically, overheating and premature aging of the electric devices.

If the mains voltage is undistorted, but non linear loads are connected to the electrical grid, the current harmonics produced will cause voltage distortions in the line impedances, and the voltage at the load terminals will also be distorted. With a distorted voltage, even linear loads absorb distorted currents. Figure 1 illustrates this.

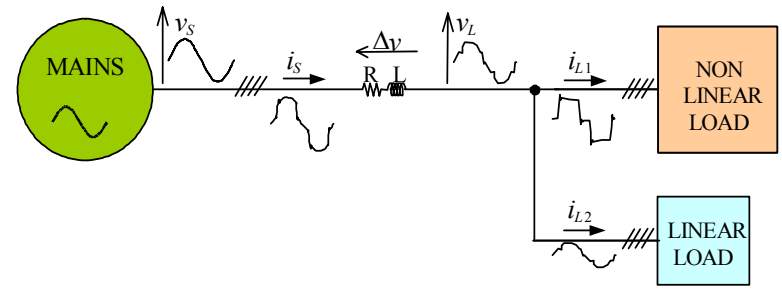

Fig. 1. Effect of nearby nonlinear load

Passive filters can be used to compensate some of the problems mentioned above, but they have some limitations, namely: they only filter the frequencies for which they have been previously tuned, its operation cannot be limited to a certain load, resonances can occur, and the electrical system can start to operate with capacitive power factor.

\section{Active power filters}

Active power filters have several advantages over passive ones: compensation is automatic, there is no risk of resonances, unity power factor (or any other desired value) can be achieved permanently and without disturbing the electrical network, they can compensate for phase unbalance, and excellent performance can be achieved. They can also be combined with passive filters (which may be already installed) in hybrid topologies, in order to diminish its rated power.

There are mainly two types of active power filters: the shunt active filter, represented in figure 2 , and the series active filter, shown in figure 3 .

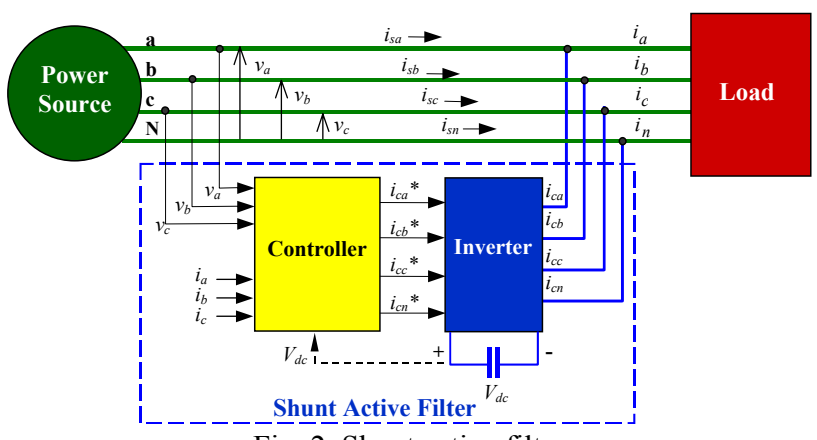

Fig. 2. Shunt active filter 


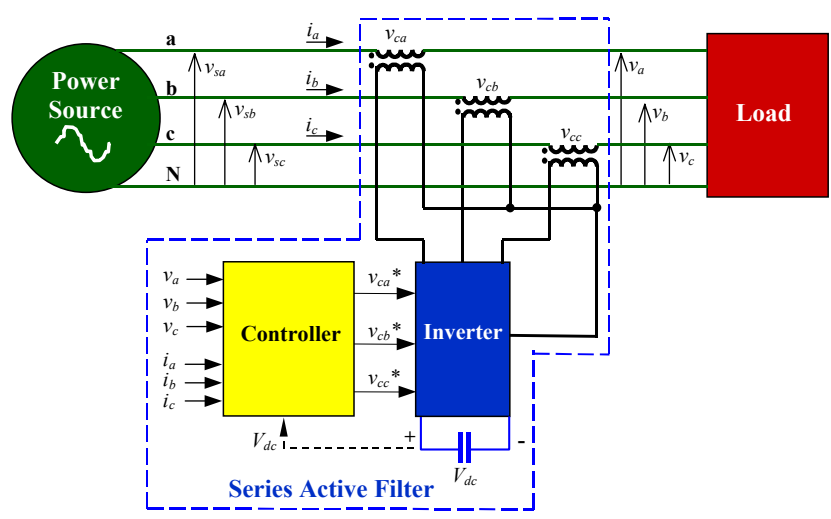

Fig. 3. Series active filter

The shunt active filter is designed to filter the line currents and the series active filter is designed to filter the mains voltages. It is also possible to combine both topologies to provide both current and voltage filtering.

\section{PC based active power filter controller}

Active power filters are usually controlled by a microcontroller or a digital signal processor (DSP) with very good results. However, here an alternative for the controller is proposed, based on a personal computer (PC) with a general purpose multifunction data acquisition board included in the PCI bus.

The major advantages of this approach are the relative low cost of the equipment, the high processing capabilities of the personal computer processor and its versatility, allowing many other tasks, such as data acquisition and logging, remote access and monitoring, integration with other systems, and many other possibilities. The personal computer used has a $733 \mathrm{MHz}$ Intel Pentium III processor with 512MByte memory. The data acquisition board is the model PCI-MIO-16E-4 manufactured by National Instruments.

Multifunction cards usually have several analogue inputs, which can be used to measure the voltages and currents values necessary to perform the control tasks, but they usually have only two analogue outputs, which can be used to generate the voltage compensation signals. So, it is important to analyse in what conditions the two compensation signals are enough for a three-phase system, because the use of a second multifunction board, if necessary, increases both the system cost and introduces time delays in the control loop.

Another limitation of these standard multifunction boards concerns the analogue inputs, since the several channels usually available are multiplexed and share the same digital to analogue converter, which causes the acquisition process to take a very significant period of time.

The control sequence is as follow: the instantaneous values of voltages and currents are acquired by the multifunction board, then the calculations are executed by the computer's microprocessor, and then, the compensating signals are outputted through the digital to analogue converters of the A/D board. These signals are then used to control the active filter power electronic converter.

\section{The control algorithms}

There were implemented two types of control algorithms: a based on p-q theory controller and a classical controller.

\section{A. Controller Based on p-q Theory}

The methods applied to control the active filters are decisive in achieving the goals of compensation, in the determination of the filter power rate, and in their dynamic and steady-state performance. Basically, the different approaches regarding the calculation of the compensation currents and voltages from the measured distorted quantities can be grouped into two classes: frequency domain and time-domain.

The frequency-domain approach implies the use of the Fourier transform and its analysis, which leads to a huge amount of calculations, making the control method very heavy. In the time-domain approach, the traditional concepts of circuit analysis and algebraic transformations associated with changes of reference frames are used, simplifying the control task.

The control algorithm based on the $\mathrm{p}-\mathrm{q}$ theory for the series active filter is proposed. Calculations are performed using the instantaneous values of the measured voltages and currents [1], [2].

The controller model executes the $p-q$ theory calculations, according to the equations (1) to (14).

First, three phase voltages and currents (fundamental positive sequence components of currents) are converted to $(\alpha, \beta, 0)$ axis:

$$
\begin{gathered}
v_{0}=\sqrt{\frac{2}{3} \cdot\left(1 / \sqrt{2} \cdot v_{a n}+1 / \sqrt{2} \cdot v_{b n}+1 / \sqrt{2} \cdot v_{c n}\right)} \\
v_{\alpha}=\sqrt{\frac{2}{3}} \cdot\left(v_{a n}-1 / 2 \cdot v_{b n}-1 / 2 \cdot v_{c n}\right) \\
v_{\beta}=\sqrt{\frac{2}{3} \cdot\left(\sqrt{3} / 2 \cdot v_{b n}-\sqrt{3} / 2 \cdot v_{c n}\right)} \\
i_{0}=\sqrt{\frac{2}{3}} \cdot\left(1 / \sqrt{2} \cdot i_{a n}+1 / \sqrt{2} \cdot i_{b n}+1 / \sqrt{2} \cdot i_{c n}\right) \\
i_{\alpha}=\sqrt{\frac{2}{3}} \cdot\left(i_{a n}-1 / 2 \cdot i_{b n}-1 / 2 \cdot i_{c n}\right) \\
i_{\beta}=\sqrt{\frac{2}{3}} \cdot\left(\sqrt{3} / 2 \cdot i_{b n}-\sqrt{3} / 2 \cdot i_{c n}\right)
\end{gathered}
$$


Assuming no neutral is present, equations (1) and (4) are null, and the real power $p$ and imaginary power $q$ are written as follow:

$$
\begin{aligned}
& p=\bar{p}+\widetilde{p}=v_{\alpha} \cdot i_{\alpha}+v_{\beta} \cdot i_{\beta} \\
& q=\bar{q}+\widetilde{q}=v_{\alpha} \cdot i_{\beta}-v_{\beta} \cdot i_{\alpha}
\end{aligned}
$$

The oscillating component of real power is obtained by subtracting the average real power from the total real power, like in equation (9):

$$
\widetilde{p}=p-\bar{p}
$$

According to the $p-q$ theory, in order to achieve the desired filtering action, it is necessary to have only the constant value of real power, and all the other components should be null. So the compensating voltages are calculated by equations (10) and (11):

$$
\begin{aligned}
& v_{c \alpha^{*}}=\frac{1}{i_{\alpha}^{2}+i_{\beta}^{2}} \cdot\left(i_{\alpha} \cdot \tilde{p}+i_{\beta} \cdot q\right) \\
& v_{c \beta^{*}}=\frac{1}{i_{\alpha}^{2}+i_{\beta}^{2}} \cdot\left(i_{\beta} \cdot \tilde{p}-i_{\alpha} \cdot q\right)
\end{aligned}
$$

Then, these voltages must be converted again to the three phase system, according to equations (12) to (14).

$$
\begin{gathered}
v_{c a^{*}}=\sqrt{\frac{2}{3}} \cdot\left(1 / \sqrt{2} \cdot v_{c 0^{*}}+v_{c \alpha^{*}}\right) \\
v_{c b^{*}}=\sqrt{\frac{2}{3}} \cdot\left(1 / \sqrt{2} \cdot v_{c 0^{*}}-1 / 2 \cdot v_{c \alpha^{*}}+\sqrt{3} / 2 \cdot v_{c \beta^{*}}\right) \\
v_{c c^{*}}=\sqrt{\frac{2}{3}} \cdot\left(1 / \sqrt{2} \cdot v_{c 0^{*}}-1 / 2 \cdot v_{c \alpha^{*}}-\sqrt{3} / 2 \cdot v_{c \beta^{*}}\right)
\end{gathered}
$$

Now, these calculated values should be used as references in the power active filter [1], [2].

The control circuit performs the calculations of the $p-q$ theory, as they work with instant values and calculations are relatively simple. However, there are two distinct ways to apply the p-q theory algorithm: one is to achieve constant power flux and the other is to eliminate voltage harmonics. If the filter is designed not to turn power constant, but to eliminate all the harmonics from the voltages, a major difficulty is introduced, because it is necessary to determine the positive sequence of the fundamental currents.

A MatLab/Simulink [4] model was built to analyse the results of the $p-q$ theory algorithm applied to a series active power filter, under different circumstances. The two following pictures show the results of compensating the three phase distorted mains voltages supplying a linear three phase load.

Figure 4 shows the three phase mains voltages distorted due to the presence of harmonics $5^{\text {th }}, 7^{\text {th }}$ and $11^{\text {th }}$.

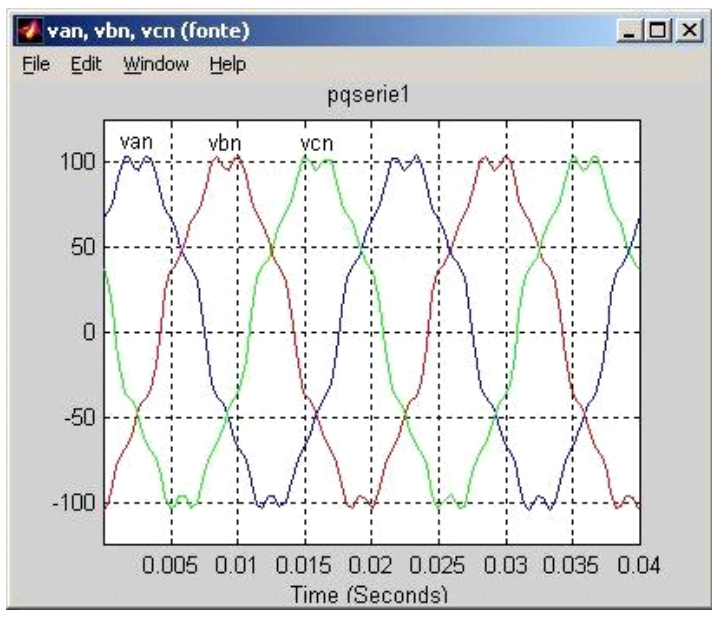

Fig. 4. Distorted mains voltages

Placing a p-q theory based, series active power filter between the mains and the load, its voltages become sinusoidal, having no distortion at all. Figure 5 shows the voltages applied to the load. As the load is linear, the currents it absorbs become undistorted too.

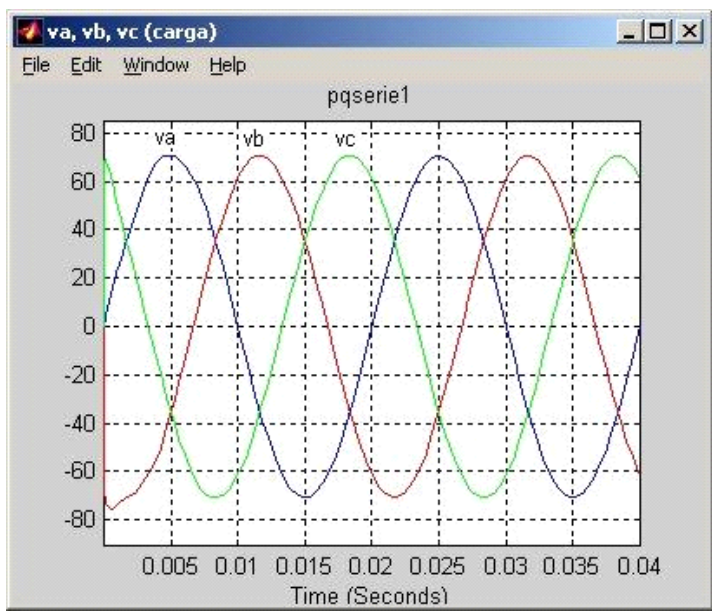

Fig. 5. Undistorted load voltages

\section{B. Classical Controller}

Very often, the main goal of the series active filter is to eliminate the voltage harmonics. In this case, the reference voltage is always known. Then, it is possible to generate the reference synchronized with the mains voltage and use another controller algorithm.

Another approach to the controller algorithm is proposed for the series active filter, based on a classical PI (proportional + integral) controller. A MatLab/Simulink model was built to analyse this alternative in a single phase series active filter, but easily transformed in a three phase system. 
The mains voltage is supposed to be distorted due to the nearby presence of a non-linear load: a rectifier with a capacitor in parallel with a resistance in the output. The reference is synchronized with main voltage.

The simulation provides promising results, as shown in the following pictures. The most significant waveforms are presented: mains voltage (figure 6), the reference (figure 7), the error signal (figure 8) and load voltage (figure 9).

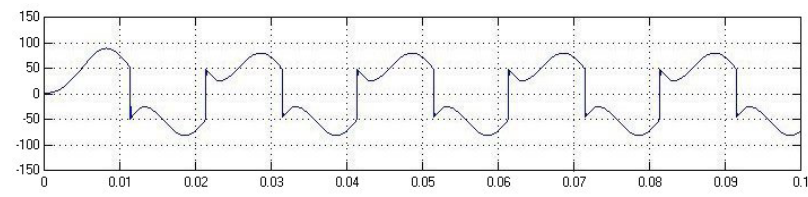

Fig. 6. Distorted main voltage

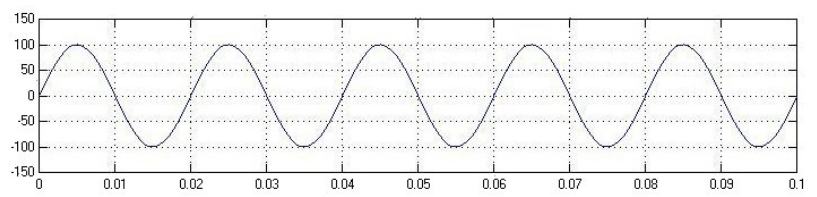

Fig. 7. Reference voltage

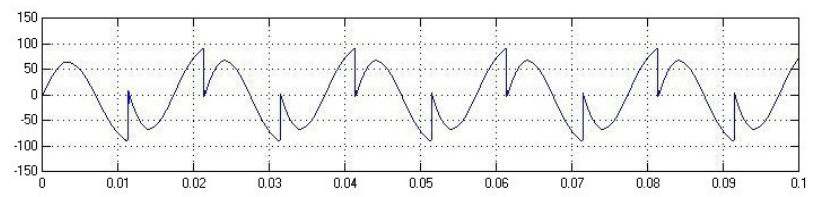

Fig. 8. Voltage error

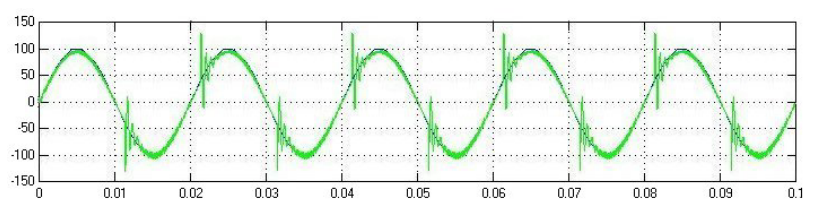

Fig. 9. Load voltage

The load voltage glitches shown in figure 9 are due to the low-pass filter used to filter the switching frequency. The resonance phenomena may be reduced or eliminated by fine tuning the low pass passive filter.

In this case, only one analogue input and one analogue output are used, diminishing the very long acquisition time and allowing the sample rate to be increased. The sampling frequency is constant, because it is possible to use the board's internal clock to establish a fixed sampling rate.

\section{Real-time control}

The proposed PC based solution presents some difficulties since the control of a power active filter requires a fast controller which does not miss samples and where all real time deadlines must always be met, or the system doesn't operate properly. This means that the application needs "hard real-time" control.
The testing programs built for Microsoft Windows, using manufacturer's device driver and function libraries, and for Linux, using real-time module RTAI, packages comedi and comedilib were programmed in $C++$ language.

\section{A. Windows and Manufacturer's Device Driver}

The acquisition board's manufacturer provides a device driver for Microsoft Windows with a large set of functions to perform several tasks. Tests made with the manufacturer's device driver and Microsoft Windows 2000 revealed poor performance: the acquisition times are very long; the set of functions available is not well suited for the application, leading to the use some software tricks; the controller's program is executed in user mode (low priority) instead of kernel mode (high priority); it is impossible to guarantee a constant sampling frequency because the number of cycles per second has a small variation [5], [6], [7].

\section{B. Linux, RTAI, Comedi and Comedilib}

Better results were achieved by another solution based on the same DAQ card using a real-time Linux kernel extension (RTAI) together with the comedi. The comedi offers an interface to lots of different DAQ cards and it consists of two complementary packages: "comedi" which implements the kernel space functionality and "comedilib" which implements the user space access to the device driver functionality.

\section{Results}

The following tables summarise the controller performance when using each of the approaches mentioned before: Windows and Linux Real. Also, a comparison is done with a microcontroller Intel 80296SA based solution, using p-q theory [3].

\section{A. Windows and Manufacturer's Device Driver}

TABLE I. - Windows performance

\begin{tabular}{|c|c|}
\hline $\begin{array}{c}\text { p-q theory } \\
\text { calculations }\end{array}$ & $\begin{array}{c}\text { floating point } \\
64 \text { bit } \\
\approx 4 \mu \mathrm{s}\end{array}$ \\
\hline Real-time & No \\
\hline $\begin{array}{c}\text { Sampling rate } \\
\text { (frequency) }\end{array}$ & $\begin{array}{c}\approx 120 \mathrm{samp} / \text { cycle } \\
(\approx 6.7 \mathrm{kHz})\end{array}$ \\
\hline Controller delay & $200 \mu \mathrm{s}$ \\
\hline
\end{tabular}

B. Linux, RTAI, Comedi and Comedilib

TABLE II. - Linux RT performance

\begin{tabular}{|c|c|}
\hline $\begin{array}{c}\text { p-q theory } \\
\text { calculations }\end{array}$ & $\begin{array}{c}\text { floating point } \\
64 \mathrm{bit} \\
4 \mu \mathrm{s}\end{array}$ \\
\hline Real-time & Yes \\
\hline $\begin{array}{c}\text { Sampling rate } \\
\text { (frequency) }\end{array}$ & $\begin{array}{c}200 \mathrm{samp} / \mathrm{cycle} \\
(10 \mathrm{kHz} \text { fixed })\end{array}$ \\
\hline Controller delay & $50 \mu \mathrm{s}$ \\
\hline
\end{tabular}




\section{Intel80296SA@40MHz Based Controller}

A shunt active filter has already been built in this department [3]. The control circuit is based on an Intel 80296 microcontroller. A summary of this controller's performance of is presented in table III.

\begin{tabular}{|c|c|}
\hline $\begin{array}{l}\mathrm{p}-\mathrm{q} \text { theory } \\
\text { calculations }\end{array}$ & $\begin{array}{c}\text { Integer } \\
8 \text { bit } \\
50 \mu \mathrm{s}\end{array}$ \\
\hline Real-time & yes \\
\hline $\begin{array}{l}\text { Sampling rate } \\
\text { (frequency) }\end{array}$ & $\begin{array}{l}\text { 300samp/cycle } \\
\text { (15 kHz fixed) }\end{array}$ \\
\hline Controller delay & "masked" \\
\hline
\end{tabular}

\section{Conclusion}

Although personal computers are relatively low cost pieces of hardware and have very fast processors, performing complicated and extensive calculations in a very short time, thy are not optimized for "hard real-time" control tasks. The main problems are related to the operating systems, and can only be solved by very skilled programmers. Another problem has to do with the slow input/output system, requiring extra data acquisition boards.. These boards are connected to the PCI bus and do not take advantage of the full processor speed and are usually designed to do data acquisition for monitoring purposes or for process control. They are very limited when performing hard real-time control.

A microprocessor based controller has much more limited calculation capabilities, but much faster input/output system.

The p-q theory is very effective and very easy to use in the shunt active filter, because the references (desired currents) are unknown and load dependent, and most of the times, the voltages can be considered almost sinusoidal.

On the contrary, this assumption is almost never true in a series active filter, i.e., the currents rarely are sinusoidal. This implies the calculation of the positive sequence of the fundamental currents, if the $p-q$ theory will be applied to compensate voltage distortion. On the other hand, the references (desired voltages) are known, allowing the use of a simple classical controller which provides good results.

\section{Future work}

The development of a PCI bus card with suitable specifications to perform this kind of real-time control, together with a set of device drivers for Microsoft Windows or Linux would be absolutely necessary to provide the best results when building a system based on a personal computer.

This board and set of drivers would also be the solution to another major difficulty: the manufacturers do not provide full information about their boards, preventing the construction of a more suitable set of device drivers.

\section{Acknowledgement}

The authors would like to thank Dr. Adriano Tavares and Dr. Carlos Silva for their help in this work.

\section{References}

[1] H. Akagi, Y. Kanazawa, A. Nabae, Generalized Theory of the Instantaneous Reactive Power in Three-Phase Circuits, IPEC'83 - Int. Power Electronics Conf., Tokyo, Japan, 1983, pp. 1375-1386.

[2] E. H. Watanabe; R. M. Stephan; M.. Aredes, "New Concepts of Instantaneous Active and Reactive Power in Electrical Systems With Generic Loads", IEEE Transactions on Power Delivery, Vol. 8, n. 2, April 1993.

[3] J. L. Afonso, H. R. Silva and J. S. Martins, "Active Filters for Power Quality Improvement", IEEE Porto Power Tech'2001, Porto, Portugal, 10-13 Set. 2001.

[4] James B. Dabney; Thomas L. Harman, Mastering SIMULINK 2, Matlab Curriculum Series, Prentice Hall 1998, ISBN 0-13-243767-8.

[5] National Instruments Corporation, DAQ DAQ-STC ${ }^{\mathrm{TM}}$ Technical Reference Manual System Timing Controller for Data Acquisition, January 1999 Edition, Part Number 340934B.

[6] National Instruments Corporation, DAQ NI-DAQ ${ }^{\mathrm{TM}}$ User Manual for PC Compatibles Version 6.9.1, Data Acquisition Software for the PC, February 2001, Edition Part Number 321644K-01.

[7] National Instruments Corporation, DAQ PCI E Series Register Level Programmer Manual Multifunction I/O Boards for PCI Bus, November 1999 Edition, Part Number 341079B-01. 